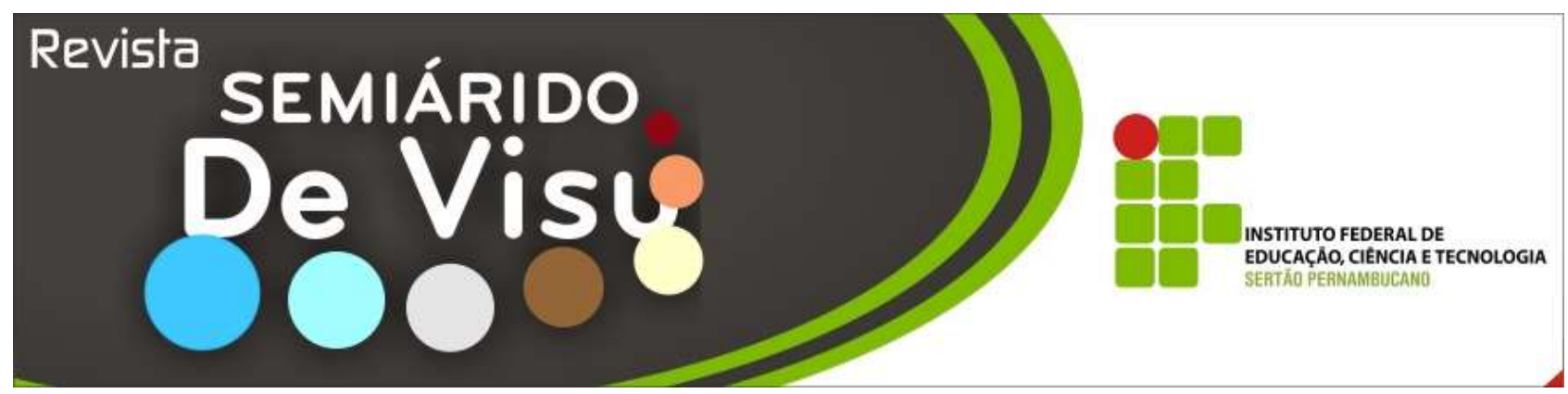

\title{
Ambiente de compartilhamento de REAs: uma proposta de modelagem, implementação e modelo de negócio
}

\author{
Paulo Henrique Bezerra Matias; Kélvya Freitas Abreu²; Francisco Kelsen de Oliveira3; Harley \\ Macedo de Mello ${ }^{4}$
1,2,3,4 Instituto Federal de Educação, Ciência e Tecnologia do Sertão Pernambucano - campus Salgueiro. BR 232, Km 508, sentido Recife, Zona Rural - Salgueiro - PE - Brasil. CEP: 56.000-000 / Telefone: (87) 3421.0050 / E-mail:
${ }^{1}$ henrique_paulo100@hotmail.com; ${ }^{2}$ kelvya.freitas@ifsertao-pe.edu.br; ${ }^{3}$ francisco.oliveira@ifsertao-pe.edu.br; ${ }^{4}$ harley.macedo@ ifsertao-pe.edu.br;

\begin{abstract}
RESUMO: Esta pesquisa objetivou propor um Ambiente de Compartilhamento de Recursos Educacionais Abertos (ACREA) a partir das necessidades de um grupo de docentes. Assim, o ACREA disponibilizou os Recursos Educacionais Abertos (REA) - materiais educacionais disponibilizados sob domínio público e licenciados de forma aberta e livre para a comunidade, que os acessam, utilizam, adaptam e redistribuem (WILEY, 2005). Pautados em Mallman e Jacques (2015), esta pesquisa entende que os REAs possuem as liberdades 5Rs: retenção, reuso, revisão, remix e redistribuição. Essas liberdades são baseadas nos quatro princípios de software livre (TAURION, 2004): executar, estudar, redistribuir e melhorar. Deste modo, por meio de questionários online foram levantados os requisitos do sistema a partir das necessidades dos docentes sobre um ambiente de compartilhamento de recursos educacionais. Os dados analisados possibilitaram a elaboração do modelo de negócio e da modelagem do ACREA em Linguagem de Modelagem Unificada (UML). Após essa etapa, o ACREA foi desenvolvido e publicado a fim de garantir o acesso a comunidade. Contudo, percebe-se ainda poucos REAs compartilhados no ACREA e a baixa participação dos docentes na utilização da ferramenta.
\end{abstract}

Palavras-chave: Recursos Educacionais Abertos, Repositório, ACREA.

\section{OER sharing environment: a proposal of modeling, implementation and business model}

\begin{abstract}
This research aimed to propose an environment of sharing open educational resources (ACREA) from the needs of a group of teachers. Thus the ACREA released the open educational resources (OER)-educational materials made available under public domain and licensed in an open and free to the community, that the access, use, adapt and redistribute (WILEY, 2005). Based in Mallman and Jacques (2015), this research considers that the OERs have 5Rs freedoms: retention, reuse, review, remix and redistribution. These freedoms are based on four principles of free software (TAURION, 2004): run, study, redistribute and improve. In this way, by means of online questionnaires were raised the system requirements from the needs of teachers about an environment of sharing of educational resources. The parsed data enabled the business model and the modeling ACREA in Unified Modeling Language (UML). After this step, the ACREA was developed and published in order to ensure access to the community. However, a few shared Areas on ACREA and low participation of teachers in the use of the tool.
\end{abstract}

key words: Open Educational Resources, Repository, ACREA. 
(MATIAS et al., 2016)

\section{Introdução}

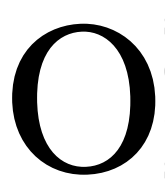
$s$ Recursos Educacionais Abertos (REA), termo proveniente do inglês Open Educational Resources (OER), são materiais educacionais disponibilizados e compartilhados de modo livre e aberto. Tais materiais podem ser cursos, módulos de aprendizagem, ferramentas de ensino, vídeos, livros, mapas, simulações, hipertextos, imagens, textos, planos de aula e outros (HILEN, 2006; DUTRA, TAROUCO, 2007; OLIVEIRA, GOMES, 2015a; OLIVEIRA; ABREU, 2016; WILEY, 2005).

Cabe destacar que os REAs evoluíram a partir do movimento Open Content, baseado na Educação Aberta, e inspirado nas liberdades dos softwares livres (do inglês Free Libre Open Source Software - FLOSS). Para Abdo (2011) e Reinehr (2012) a Educação Aberta pode ser modelada em camadas: física (computadores, software, acesso à internet etc.), lógica (testes, módulos, livros didáticos e artigos de pesquisa), simbólica (processos de aprendizado, relações internas e cruzadas entre alunos e professores) e humana (prática pedagógica). Os autores ainda enfatizam a relevância dos aspectos políticos para a promoção da adoção dos REAs, entre eles o reuso, a reforma da educação para um modelo aberto e o incentivo à produção de REAs por instituições.

As liberdades dos FLOSS contribuíram com os REAs para executar, estudar, adaptar, redistribuir e distribuir suas adaptações (ROSEN, 2005; FSF, 2007; DUTRA, TAROUCO, 2007). Assim, os REAs se consolidaram no decorrer do tempo a partir dos preceitos de FOSS e se mostraram como um importante instrumento para disseminação do conhecimento em universidades, independente da modalidade do curso, a saber: presencial, semipresencial, à distância ou híbrido (ROSEN, 2005; FSF, 2007; DUTRA, TAROUCO, 2007).

Dessa forma, Mallmann e Jacques (2015) apresentam as liberdades (5R) dos REAs a partir dos princípios apresentados por Merril (2000) e Wiley, Gibson e Recker (2002): retenção, reuso, revisão, remix e redistribuição. Primeiramente, a retenção diz respeito à permissão de baixar e armazenar cópias do arquivo em formato digital ou não. Já o reuso é a possibilidade de usar e reusar o recurso quantas vezes quiser; enquanto a revisão possibilita que outras pessoas apresentem melhorias ou propostas de aperfeiçoamentos dos materiais de tal modo a garantir os créditos aos autores iniciais e assegurar o cumprimento das regras de licenciamento do recurso. Com relação ao remix, esse propicia as adequações dos materiais, ao passo que a redistribuição autoriza que usuários possam distribuir as cópias do material.

Quanto ao uso de licenças desses recursos, a Creative Commons é uma das mais recentes e mais importante forma de licenciamento, devido essa possuir licenças bem definidas e de grande quantidade de informação fornecida. Portanto, a Creative Commons se tornou a mais utilizada por autores interessados em permitir o uso de sua obra de forma livre e aberta (LIANG, 2004), uma vez que se facilita o processo de referência na obra de outros autores.

Tais licenças, baseadas no modelo da Creative Commons, permitem que o autor escolha a melhor forma de se licenciar um conteúdo, já que essa permite que o conteúdo seja utilizado para fins comerciais ou não, podendo ainda ser modificada sem restrições, etc.

Para organizar tais conteúdos, costumamse utilizar sistemas de gerenciamento de aprendizagem (SGA), sejam os Ambientes Virtuais de Aprendizagem (AVA) ou Redes Sociais Educacionais (RSE), pois os AVAs ou RSEs são utilizados para gerenciar cursos, disciplinas, discentes, docentes e materiais didáticos, então os REAs são incluídos nas bibliotecas dos SGA, conforme suas licenças (DUTRA, TAROUCO, 2007). Há ainda projetos como Latin, Projeto do Livro Didático Público e OpenCourseWare (OCW), que organizam as bibliotecas de REAs em repositórios online com funções e recursos específicos aos seus respectivos objetivos de difusão de materiais.

O Projeto Latin, por exemplo, mantém uma biblioteca de e-books livres, principalmente, de conteúdos de cursos 
(MATIAS et al., 2016)

superiores. Enquanto, o Projeto de Livro Didático Público é uma biblioteca virtual com livros didáticos abertos (LDA) de diversas disciplinas e demais materiais de suporte às atividades pedagógicas. Já a iniciativa OCW foi criada e é adotada atualmente em instituições como o Massachusetts Institute of Technology (MIT), que criou o MIT OCW com o objetivo de compartilhar materiais e videoaulas dos cursos de graduação e pós-graduação para quaisquer usuários (OLIVEIRA, 2010; DUTRA, TAROUCO, 2007).

Dessa forma, Amiel, Orey e West (2011) salientam a importância dos repositórios ao garantirem $o$ acesso aos REAs de forma organizada, além de motivar a criação de novos recursos e, por consequência, propiciar a inovação na prática pedagógica. Contudo, os autores ou desenvolvedores de REAs devem se atentar para a organização e o planejamento com foco na integração de tecnologias no processo de ensino e aprendizagem, a fim de uma melhor interação entre os usuários participantes com os conteúdos disponibilizados (MALLMANN et al., 2013). Isso demonstra a necessidade de não apenas converter um material impresso em um material digital ou mesmo utilizar metodologias semelhantes para ambos os casos, mas planejar a concepção ou uso de um REA em conformidade com a necessidade existente, tal qual ocorre com o uso de Recursos Educacionais Digitais (RED), cuja a atuação de profissionais multidisciplinares está em proporcionar materiais digitais com o valor agregado e benefícios proporcionados pelo uso de Tecnologias Digitais de Informação e Comunicação (TDICs).

Conforme Oliveira et al. (2011), a ampliação do acesso à Internet para a população tornou acessível diversos conteúdos, inclusive educacionais, bem como a disponibilidade de ferramentas de autoria para materiais textuais, audiovisuais, animações ou simulações, de forma fácil e sem necessidade de profundos conhecimentos de Informática para usá-las.

Nessa perspectiva, os REAs também recebem colaboração desse modelo, já que podem ser acessados livremente, utilizados, editados ou redistribuídos, conforme sua licença, a partir de um ambiente online e centralizado que reduz custos com logística de entrega de materiais e facilita as atualizações desses recursos.

Dessa forma, o objetivo desta investigação foi propor o Ambiente de Compartilhamento de REAs (ACREA) a partir das necessidades elencadas por um grupo de docentes. O ACREA visou oferecer possibilidades de armazenamento, hospedagem, divulgação, compartilhamento e avaliação (por pares e às cegas) de REAs por professores, estudantes, pesquisadores e demais interessados. Dessa forma, teria um local centralizado para que os usuários pudessem ter acesso aos REAs, bem como colaborar com melhorias de projetos ou materiais.

Para entender as necessidades dos usuários, levantou-se os requisitos funcionais que descrevessem as funções do software/produto cujo escopo fosse beneficiar os usuários finais (PAULA FILHO, 2009). Logo após a reunião desses requisitos, modelou-se a ferramenta para proporcionar uma melhor compreensão do que seria desenvolvido (MAXIM; PRESSMAN, 2016).

Cumpre sinalizar que a modelagem de um software deve ser capaz de representar as informações que este transforma, sua arquitetura; as funções que possibilitam a transformação; as características desejadas pelos usuários e ainda descrever como o sistema irá se comportar de acordo com as transformações que irão ocorrer.

Desse modo esse procedimento permite envolver o usuário na especificação do banco de dados (BD), que de acordo com a prática da engenharia de software, o envolvimento do usuário na especificação do software aumenta a qualidade produzida. A partir disso infere-se então que o usuário é aquele que melhor conhece a organização e, portanto, aquele que melhor conhece os requisitos que o software deve preencher. Logo, utilizam-se modelos conceituais pois os mesmos descrevem a organização e, portanto, são mais simples de compreender por usuários leigos em Informática (HEUSER, 2009). 
(MATIAS et al., 2016)

A Linguagem Unificada de Modelagem (UML) é a principal referência para elaboração de modelagem de software. Para isso, o diagrama de caso de uso (use case) permite documentar o sistema a partir do ponto de vista do usuário, possibilita de igual forma $\mathrm{o}$ sequenciamento das interações entre um sistema e os agentes externos utilizadores deste, definindo o uso de uma parte da funcionalidade de um sistema, sem a necessidade de apresentar nesta etapa a estrutura e o comportamento interno (BEZERRA, 2014).

Segundo Heuser (2009), um modelo conceitual é uma descrição do BD de forma independente de sua implementação em um Sistema Gerenciador de Banco de Dados (SGBD), já que esse registra quais dados podem aparecer no $\mathrm{BD}$, mas não registra como estes dados estão armazenados a nível de SGBD.

Nessa linha de raciocínio, a seguir esboçam-se o trilhar desta investigação.

\section{Materiais e Métodos}

A presente pesquisa caracterizou-se como exploratória, pois conheceu o estado atual de desenvolvimento, compartilhamento e uso dos REAs. Para tal finalidade, foi realizada uma pesquisa bibliográfica para fundamentação teórica a fim de identificar os aspectos, como, ambientes de compartilhamentos existentes, as principais licenças usadas, quais os possíveis usuários e, em seguida, feito um levantamento de requisitos com a amostra da pesquisa, formada por 16 professores participantes do Curso de Recursos Educacionais Abertos (CREA).

O CREA foi um curso de extensão com duração de 40h ministrado na modalidade à distância por professores do Campus Salgueiro do Instituto Federal de Educação, Ciência e Tecnologia do Sertão Pernambucano (IF Sertão-PE) e contemplou três módulos sobre REAs (OLIVEIRA; ABREU; SILVA, 2015):

- Módulo 01: Conceitos, definições e tecnologias e licenças de REAs

- Módulo 02: Modelos de negócios, repositórios e ambientes de compartilhamento de exemplos de REAs

- Módulo 03: Práticas educacionais abertas (PEA).

Para a coleta de dados e levantamento dos requisitos, foram utilizados questionários online semiestruturados e abertos (FLICK, 2013). As respostas eram organizadas em planilhas eletrônicas com o objetivo de facilitar a análise desses dados após esta etapa. Além disso, houve entrevistas com docentes interessados na área de TDICs com viés educacional, pois assim seriam garantidas respostas mais balizadas por profissionais atuantes na área, conforme a descrição de entrevista com especialistas de Flick (2013).

Marconi e Lakatos (2002) relatam a importância da coleta de dados a partir de questionários, porque podem garantir vantagens como: economia de tempo, abrangência de grande número de pessoas de forma simultânea, abrangência de área geográfica mais ampla, obtenção de resposta mais precisas, maior liberdade nas respostas, maior segurança, menor risco de distorção, mais tempo para responder as questões, maior uniformidade na avaliação e obtenção de respostas que materialmente seriam inacessíveis.

O Google Docs foi utilizado para a elaboração do questionário online semiestruturado para levantamento de requisitos, porque é uma ferramenta online, gratuita e permite a criação de documentos, formulários, planilhas e slides, inclusive as respostas já ficam disponíveis em planilha eletrônica compartilhada entre os pesquisadores envolvidos na referida investigação.

O questionário ficou disponível durante as duas primeiras semanas do CREA (https://goo.gl/bxCgZI), visando identificar o perfil dos usuários, levantar as funcionalidades e características de um ambiente de compartilhamento de recursos educacionais.

Os requisitos funcionais do ambiente foram levantados pelas análises e interpretações das respostas dos questionários e entrevistas sobre as descrições das funções do software.

Então, uma modelagem UML de caso de uso foi elaborada por meio da ferramenta gratuita Computer-Aided Software Engineering 
(MATIAS et al., 2016)

(CASE) Astah. A partir da modelagem de caso de uso, foi feito o modelo conceitual com a ferramenta brModelo se utilizando a abordagem Entidade-Relacionamento (ER), pois é a mais difundida para modelagem (HEUSER, 2009).

Além disso, foi elaborada uma proposta de representação do modelo de negócio do ACREA com o intuito de melhor divulgar para a comunidade de professores e produtores de conteúdo a forma de inclusão dos materiais no ACREA, as etapas do processo e a forma de avaliação dos REAs a serem incluídos no sistema.

Por fim, o sistema de gerenciamento de conteúdos (do inglês Content Management System - CMS) Wordpress foi utilizado para apresentar um protótipo do ACREA com as principais funcionalidades elencadas.

\section{Resultados e discussões}

As análises das respostas dos usuários do ACREA evidenciaram a necessidade do ambiente estar disponível a todo momento; responder rapidamente às solicitações; ter um layout organizado, intuitivo e fácil de utilizar; ter características responsivas para que pudessem ser utilizadas a partir de computadores, tablets e smartphones e garantir a segurança e privacidade dos usuários do ACREA, de tal forma a não divulgar dados cadastrados para terceiros.

Quanto ao licenciamento dos REAs, demonstrou-se a necessidade de orientação dos usuários sobre a legislação pertinente ao uso e compartilhamento desses recursos, inclusive com a possibilidade de haver tutoriais informativos e a função de escolha de licenças no instante de compartilhar o material, conforme o interesse do autor e as liberdades dos REAs. Já em relação às buscas por REAs, percebeu-se a inexistência de um repositório de referência para tais materiais; assim foi informado que os buscadores na Internet como Google e Bing, e as redes sociais foram as fontes principais para se encontrar os REAs com $75 \%$ de preferência em ambos, pelos integrantes da amostra da pesquisa.
No que tange aos mecanismos de divulgação dos REAs, as sugestões foram unanimes em ocorrer através de portais de conteúdos educacionais e redes sociais educacionais. Enquanto houve $75 \%$ dos pesquisados relatando ocorrer em: repositórios de software, redes sociais, propagandas em revistas na área de educação e envio de e-mails para listas ou grupos de profissionais da área educacional.

No que diz respeito à promoção de compartilhamento de REAs, foram apresentadas respostas para que utilizassem grupos ou páginas em redes sociais para discussões sobre a importância dos REAs. Ao passo que em relação à promoção do uso efetivo desses recursos pelos professores, evidenciou-se a necessidade de capacitações sobre uso e desenvolvimento de REAs para professores, formação ou aperfeiçoamento profissional no uso de novas tecnologias e inovação em metodologia educacional, e divulgações de práticas pedagógicas ou casos de sucesso com REA's.

Cabe destacar que todos os participantes da pesquisa já utilizaram algum repositório de REA, enquanto a metade dessa amostra utilizou alguma ferramenta de autoria para produção de materiais.

Os participantes mencionaram também a importância da integração entre repositórios de REAs, ferramentas de autoria e AVAs ou RSE, de tal forma que a ferramenta ou repositório não seja exclusivo de um ambiente e os recursos desenvolvidos por uma ferramenta possam ser disponibilizados nos diversos repositórios e sejam compatíveis independente do ambiente educacional de ensino utilizado, como Amadeus, Moodle, Openredu, Edmodo e outros.

Para proporcionar o aumento do desenvolvimento desses recursos, os participantes da amostra sugeriram um ambiente de uso e desenvolvimento simples, fácil, intuitiva e sem requerer profundos conhecimentos de programação. Enquanto para possibilitar a maior reutilização de recursos pelos professores foi recomendada maior colaboração para disponibilizar cada vez mais recursos educacionais de forma livre, bem 
(MATIAS et al., 2016)

como suporte para inclusão de profissionais com menor habilidade em tecnologia.

Um modelo de caso de uso com as funcionalidades do sistema foi proposto a partir das análises das respostas obtidas no questionário de levantamento de requisitos e na entrevista. Para isso foram elaborados 5 casos de usos do ACREA: [UC1] - Cadastro usuário (Figura 1), [UC2] - Cadastro de REA (Figura 2), [UC3] -Desenvolvimento (Figura 3), [UC4] - Repositório (Figura 4) e [UC5] - Avaliação (Figura 5).

Figura 1: [UC1] - Cadastro usuário.

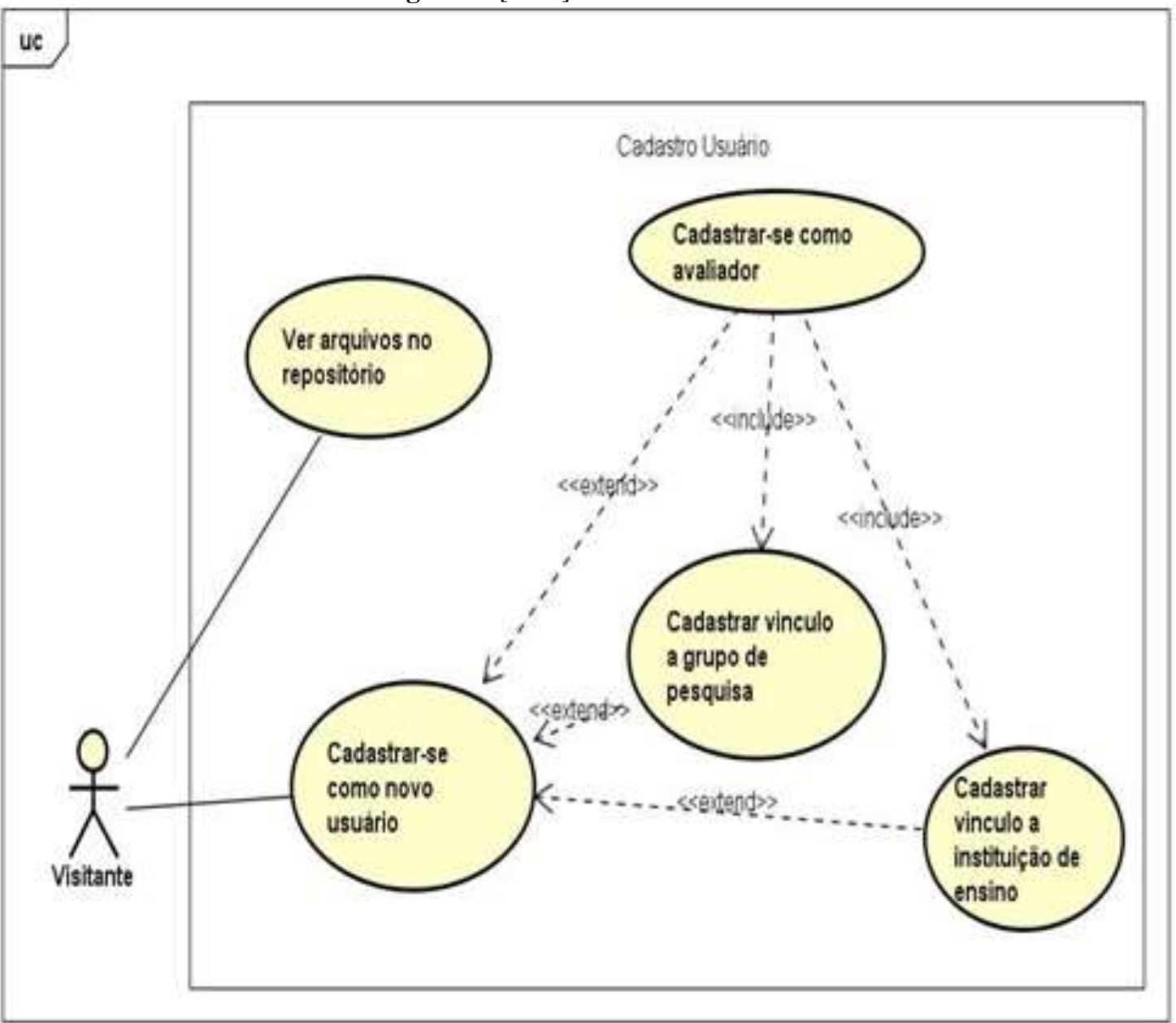

Fonte: Pesquisa direta.

Na modelagem de [UC1], Figura 1, um visitante do ACREA não cadastrado poderá apenas ver quais arquivos estão disponíveis no repositório, todavia $\mathrm{o}$ usuário tem a possibilidade de se cadastrar como um novo. A partir do seu cadastro, o usuário pode, opcionalmente, cadastrar um vínculo a um grupo de pesquisa e também cadastrar vínculo a uma instituição de ensino. Esse ainda possui a opção de se cadastrar como usuário avaliador, para que possa avaliar materiais enviados, porém só poderá se cadastrar como usuário avaliador caso tenha cadastrado um vínculo à um grupo de pesquisa e um vínculo à uma instituição de ensino.

Tal restrição tem por objetivo garantir controle de qualidade dos materiais postados no repositório, de modo que esse controle comece restringindo quem poderá avaliar os materiais postados no ambiente. 
(MATIAS et al., 2016)

Figura 2: [UC2] - Cadastro REA.

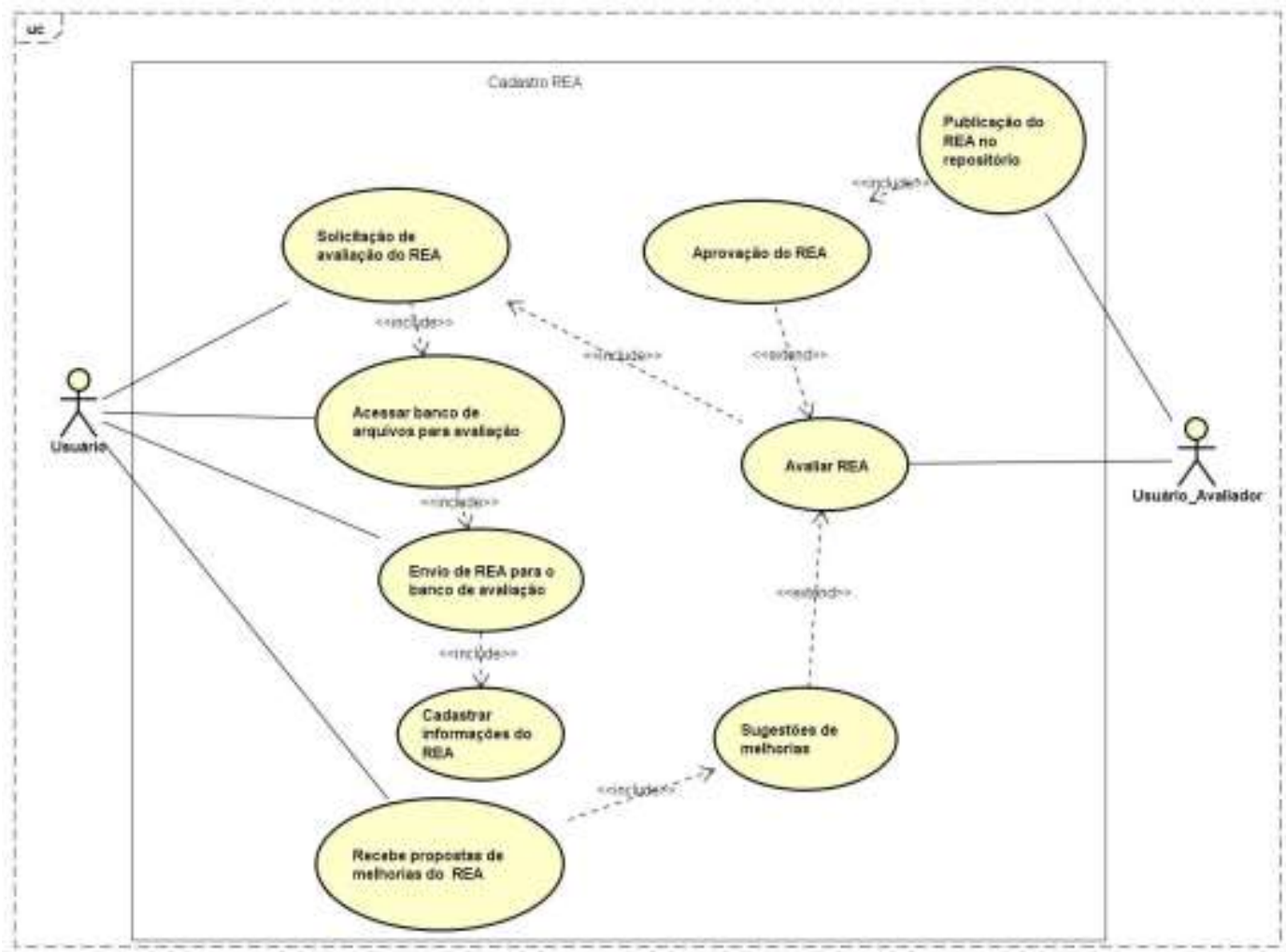

Fonte: Pesquisa direta.

No segundo modelo [UC2] da Figura 2, o usuário pode cadastrar seu material no repositório a partir de algumas funções: envio de REA para o banco de avaliação, acessar banco de arquivos para avaliação, solicitação de avaliação do REA e receber propostas de melhorias do REA.

O usuário possui uma generalização que é o usuário Avaliador, foi visto na Figura 1 a possibilidade de cadastro como Usuário avaliador. $\mathrm{O}$ usuário pode ter acesso ao repositório e suas funcionalidades (Figura 4) e também realizar o Cadastro de REA (Figura 2).

$\mathrm{O}$ usuário Avaliador além de realizar as funções do Usuário, poderá também avaliar um REA, de acordo com a Figura 2, mas para isso é necessário que o mesmo cadastre sua área de atuação para que possa avaliar materiais que são da sua área de conhecimento.

Para que o REA seja avaliado conforme o [UC2], é necessário que o material já tenha sido concluído por meio da ferramenta de autoria do [UC3] ou tenha sido realizado o upload no ACREA, pois apenas ficará disponível para os demais usuários, quando receber a aprovação dos pares.
A avaliação por pares ocorre de acordo com o modelo double blind peer review, que possibilita a avaliação por pelo menos da área do material para conferir se está atendendo aos metadados cadastrados pelo autor. Esses são escolhidos dentre autores cadastrados no ACREA e que atuem na mesma área do REA submetido. Esses são designados pelo administrador do ACREA, que também se responsabiliza em omitir as informações para evitar o reconhecimento da autoria do material.

Os avaliadores poderão aceitar ou não avaliar tal material, enquanto o administrador do ACREA realiza diversas rodadas de designações de avaliadores até obter os pareceres de pelo menos dois avaliadores da área do recurso. Quando houver divergência entre os pareceres dos avaliadores, um terceiro avaliador é designado para suprimir tal dúvida. Logo depois, os recursos são analisados por avaliadores para uma checagem de segurança para evitar a inclusão de softwares maliciosos nos REAs disponíveis no ACREA.

Após essa avaliação, o REA pode ser aceito diretamente ou ter sugestões de melhorias ou ser reprovado nesta rodada. 
(MATIAS et al., 2016)

Figura 3: [UC3] - Desenvolvimento.

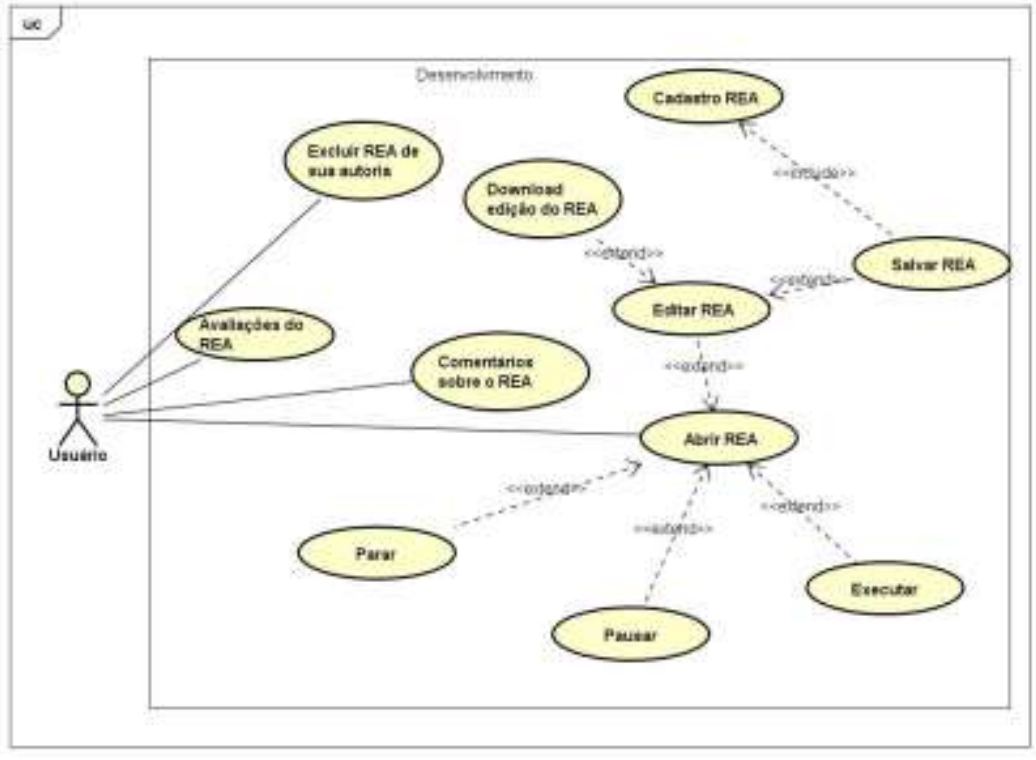

Fonte: Pesquisa direta.

Assim, ficará disponível no repositório, caso seja aprovado. Se tiver aprovado mediante alterações, será analisado a fim de conferir se as sugestões foram atendidas e posteriormente publicado.

No [UC3] - Desenvolvimento (Figura 3), o usuário poderá desenvolver seus REAs na plataforma, excluí-los, editá-los, avaliar REA de outros usuários, conforme o [UC5] (Figura 5), apresentar comentários sobre o recurso disponibilizados pelos pares ou abri-los e utilizar as funções disponíveis.

Sugere-se a adoção do IMS - Learning Design (IMS-LD) como especificação necessária para padronização dos recursos desenvolvidos na plataforma e garantir o acesso em outros ambientes ou edição em outras ferramentas de autoria (OLIVEIRA; GOMES, 2015b; IMS, 2003).

Figura 4: [UC4] - Repositório

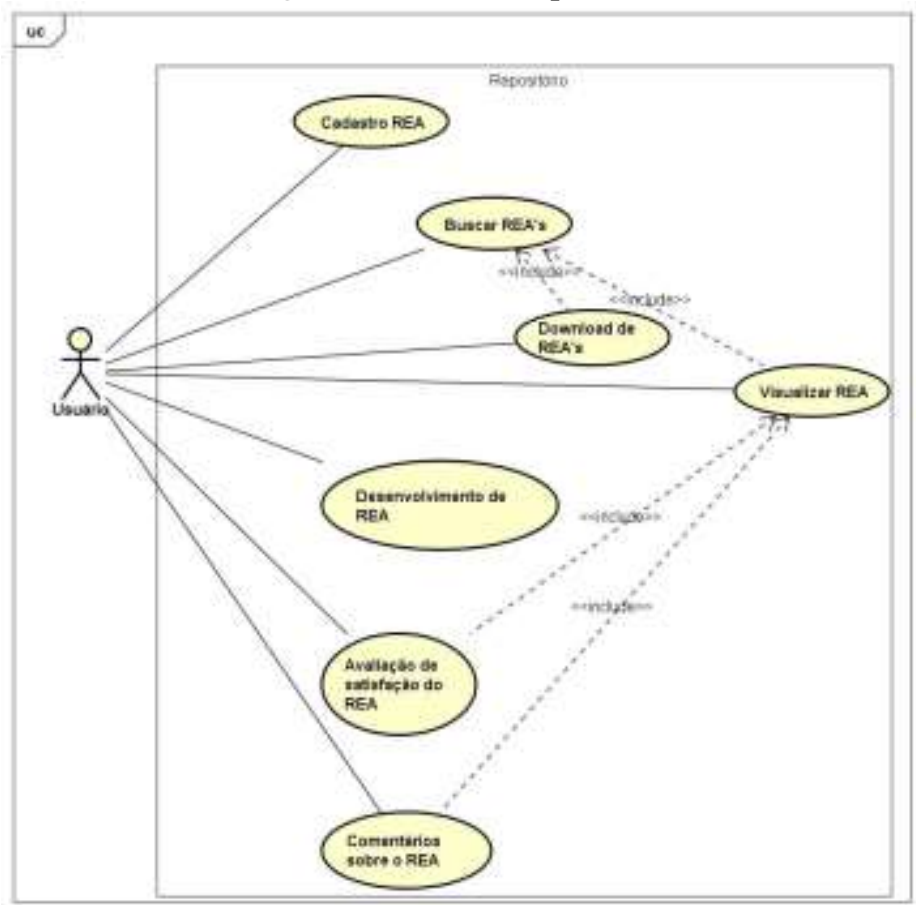

Fonte: Pesquisa direta. 
(MATIAS et al., 2016)

No caso de um documento, o usuário poderá editá-lo na própria plataforma, realizar download da versão editada ou salvá-lo no repositório [UC4] (Figura 4), porém apenas mediante o cadastro inicial dos metadados do REA [UC2].

O [UC4] trata da modelagem das funções do usuário dentro do repositório de arquivos, que poderá cadastrar um REA, todavia para isso será necessário passar pelo processo descrito na Figura 2.

Já o [UC5] representa a possibilidade de apresentação de avaliação pelos avaliadores ou comentários pelos pares (Figura 5). O usuário poderá buscar de REAs, visualizar, baixar do arquivo encontrado, desenvolver REA, conforme a [UC3], ou apresentar avaliação e comentários sobre o material.

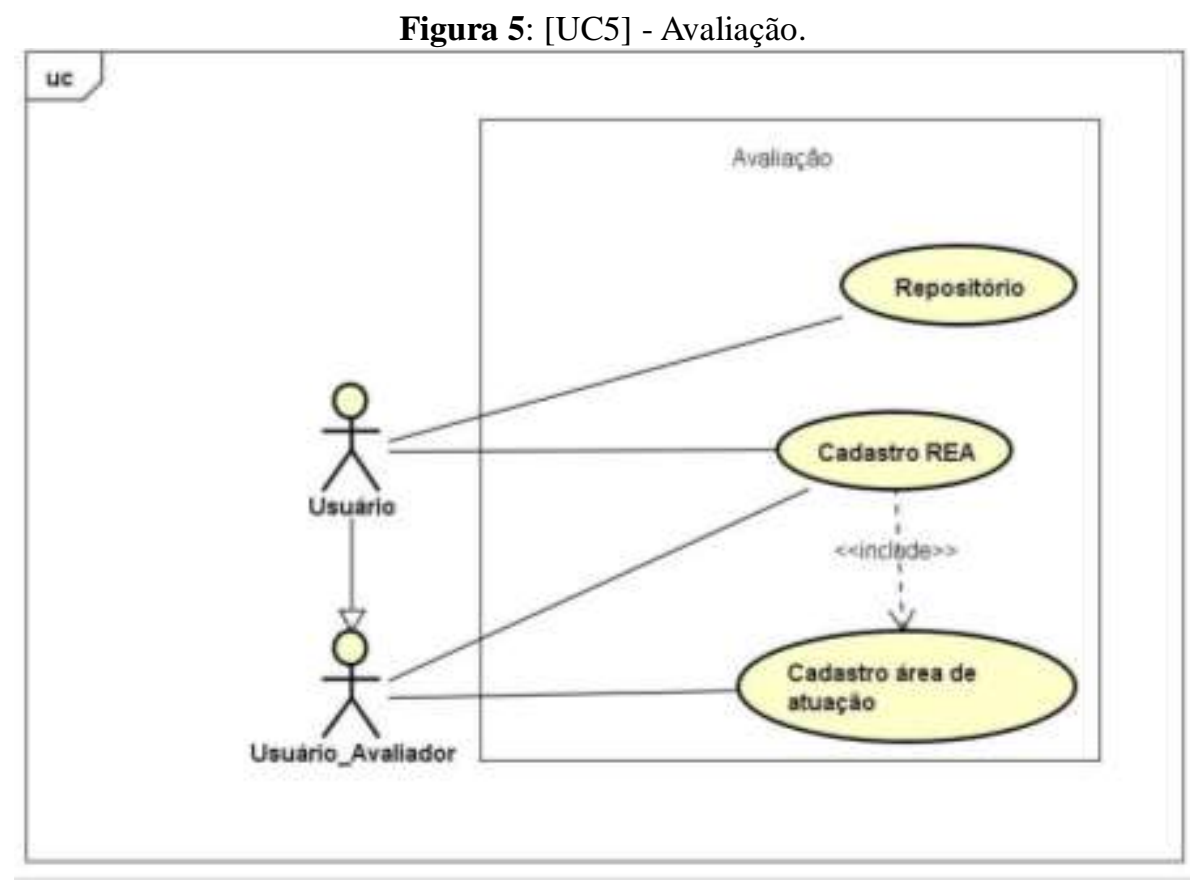

Fonte: Pesquisa direta.

A partir da modelagem de caso de uso foi feito o modelo conceitual, utilizando-se a abordagem Entidade-Relacionamento (ER), a fim de definir quais dados serão armazenados no BD (Figura 6). Assim, foram definidas as entidades principais, suas relações, atributos, generalizações e cardinalidades.

O usuário possui os atributos Nome, Telefone, Formação Acadêmica e E-mail. Possui ainda como atributos Área de conhecimento, de modo que tal atributo possui cardinalidade $(1, n)$, o que significa que $o$ usuário pode cadastrar pelo menos uma área do conhecimento, ou pode cadastrar muitas áreas do conhecimento. O usuário possui como atributo identificador o Código de Usuário e dois atributos opcionais, Vínculo a Grupo de pesquisa e Vínculo a Instituição de Ensino, tais atributos possuem cardinalidades $(0, n)$ o que significa que esse pode possuir muitos vínculos a instituiçõos de ensino e grupos de pesquisa, ou nenhum vínculo.

O usuário pode ter uma generalização e ser também usuário avaliador, conforme a Figura 1. O usuário avaliador possui os mesmos atributos que o usuário, todavia os atributos Vínculo a Grupo de Pesquisa e Vínculo a Instituição de ensino passam a ser obrigatórios para que o usuário se torne avaliador.

Tanto o usuário como o usuário avaliador podem participar da ocorrência de entidade Avaliação. Tal ocorrência possui como atributos Comentários e Sugestões de Melhorias, e possui como atributos identificadores avaliador e desenvolvedor. Nessa ocorrência participam o usuário que desenvolveu o REA, o REA cadastrado pelo usuário e o usuário avaliador, de modo que 
possa guardar as informações relativas ao resultado da avaliação.

$\mathrm{O}$ usuário pode cadastrar nenhum ou muitos REAs. Para que um REA exista, é necessário que possua pelo menos um usuário que o cadastrou, ou muitos usuários que o cadastraram. O mesmo possui os atributos Tipo de REA, Licença, Contribuidores, Área de Conhecimento, Desenvolvedor e Formato.

REA possui uma generalização parcial Mídia, ou seja, quando um REA for uma mídia, ele também possuirá como atributo Tempo de execução. A entidade REA pode estar associada a uma Biblioteca, todavia para que exista uma biblioteca é necessário que tenha uma ocorrência de entidade entre Usuário e Biblioteca.

Um REA pode estar associado a nenhuma Biblioteca, ou pode estar associado a muitas bibliotecas, enquanto uma Biblioteca deve estar associada a pelo menos um REA ou pode ter muitos REAs.

Um Usuário pode ter nenhuma ocorrência de Biblioteca, ou pode ter no máximo uma ocorrência de Biblioteca. Enquanto a Biblioteca possui no mínimo uma ocorrência de Usuário e no máximo uma ocorrência também.

Figura 6: Modelagem ER.

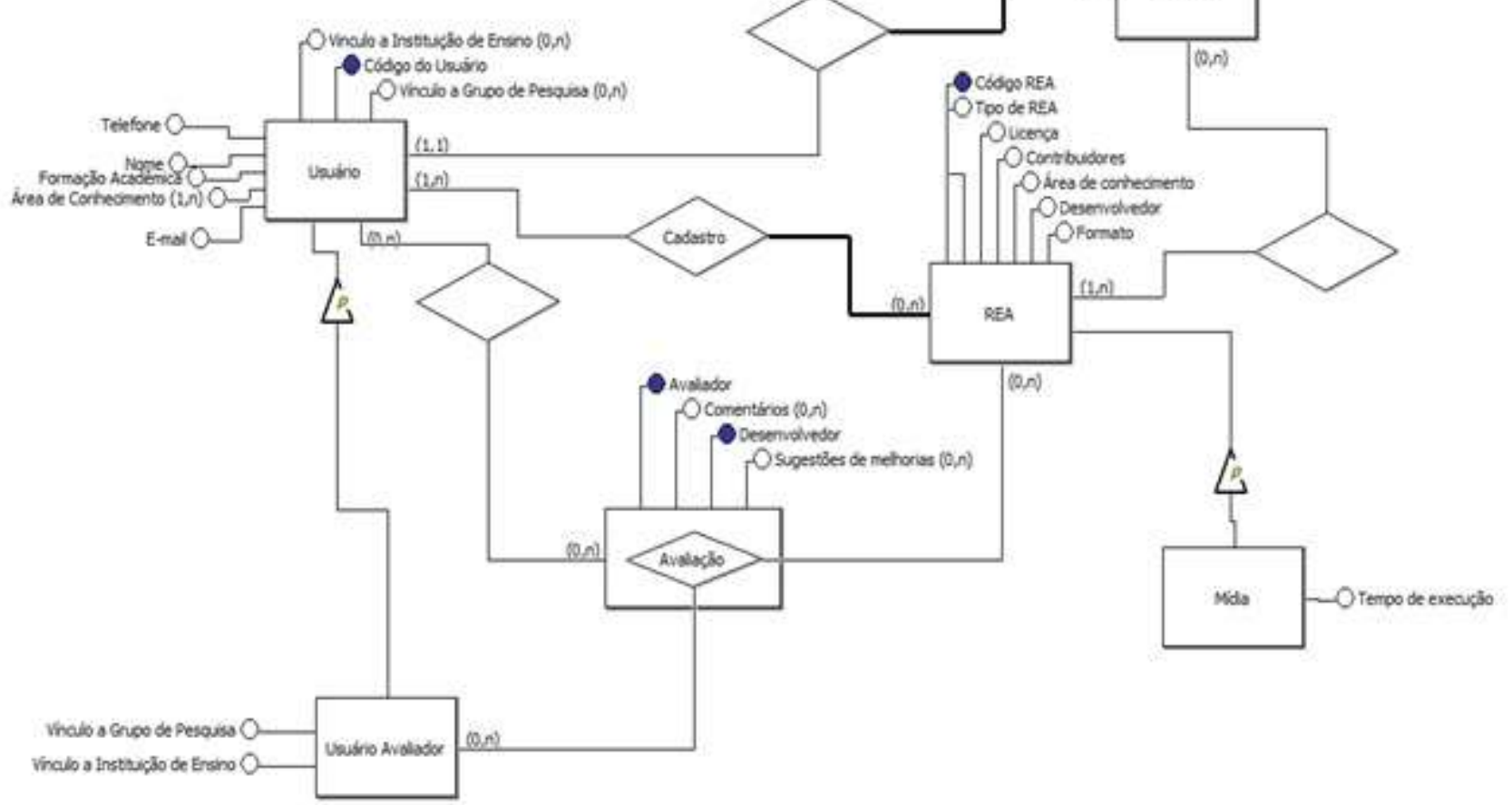

Fonte: Pesquisa direta.

A partir das modelagens e do levantamento de requisitos, foi elaborado um modelo de negócio (Figura 7) para que o usuário possua uma melhor compreensão do funcionamento geral do ambiente a partir de adaptação do modelo do Oliveira e Gomes (2015c), que ainda não apresentava a possibilidade da retenção para compor a liberdade $5 \mathrm{R}$.

O usuário irá enviar para o sistema um REA, e de acordo com a licença utilizada será avaliado se o material possui as liberdades de reuso, revisão, remixagem, redistribuição e retenção. Caso não possua tais liberdades ele retornará para o usuário. Se possuir, ele será enviado para avaliação. Caso ele seja aprovado por pelo menos dois avaliadores, ele seguirá para publicação. Caso isso não aconteça, ele retornará para o seu autor com sugestões de melhorias apresentadas pelos avaliadores.

Após aprovação o material será publicado no ACREA e estará disponível aos demais usuários. Tais usuários podem utilizar esse material e fazer uma avaliação de satisfação, 
(MATIAS et al., 2016)

avaliação essa que será dada como retorno para o usuário que o desenvolveu para que possa ser aperfeiçoado.

A partir da modelagem proposta é possível que os usuários possam sugerir modificações para que o ACREA seja implementado de acordo com tais sugestões. Para divulgar a ideia foi construído um site com Wordpress (Figura 8), que funciona como um protótipo da ferramenta implementada.

Figura 7: Modelo de Negócio.

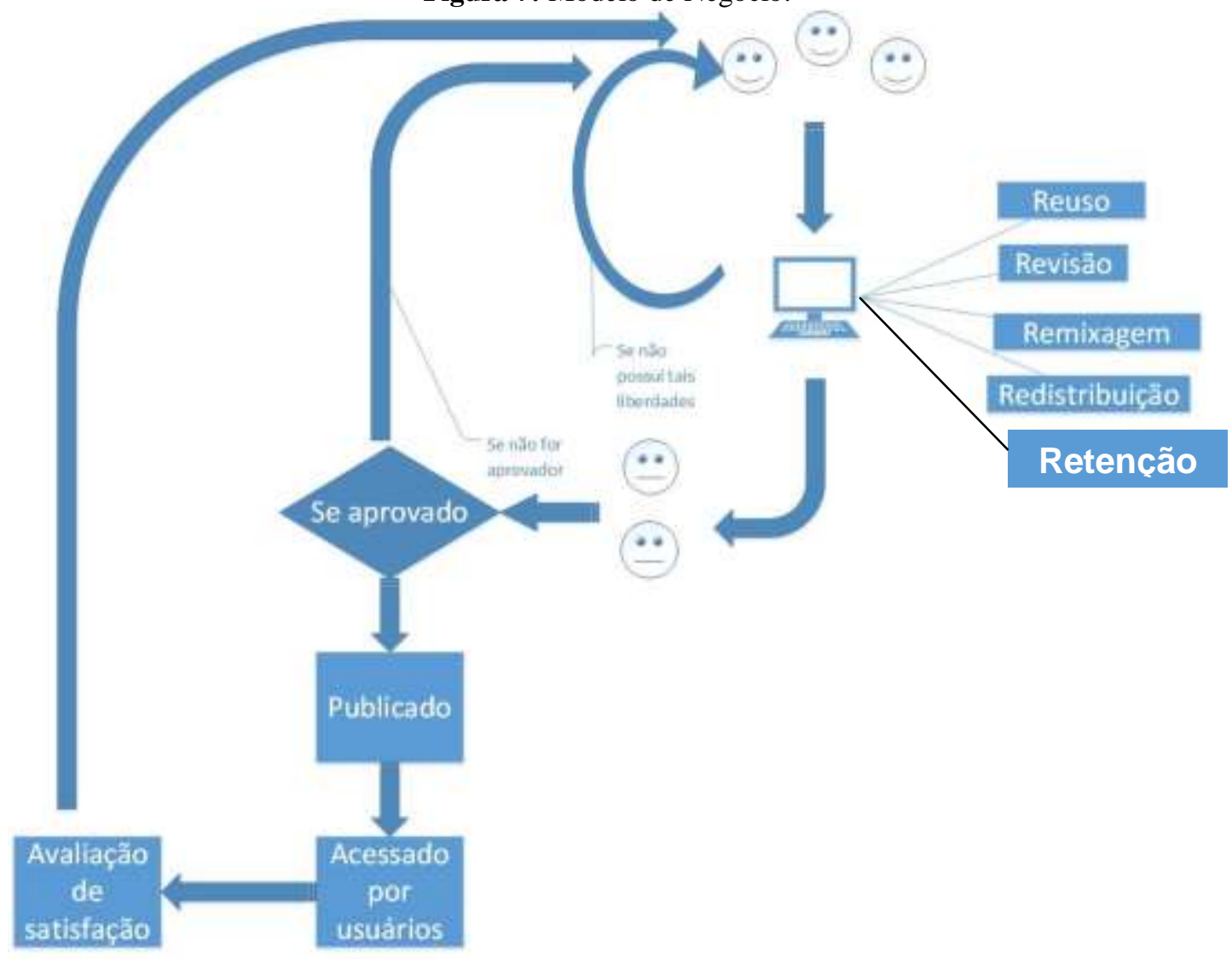

Fonte: Pesquisa direta.

A página do ACREA foi projetada para apresentar não apenas recursos, mas também definições, materiais de estudo, notícias sobre o assunto, compartilhamento de experiências de uso dos REAs e está disponível pelo link: https://acrea2015.wordpress.com/.

Figura 8: Página inicial do ACREA.

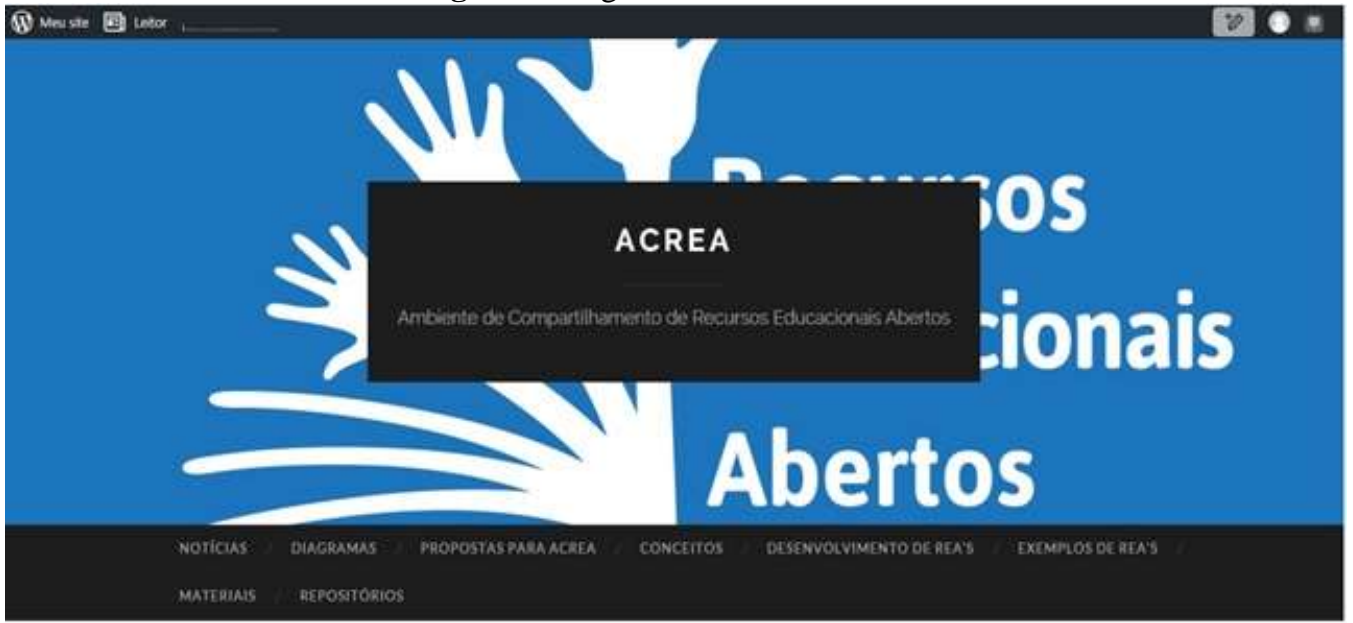

Fonte: Pesquisa direta. 
(MATIAS et al., 2016)

No menu de desenvolvimento de REAs são colocadas ferramentas que permitam a criação de REAs de forma prática e online, de acordo com os professores os formatos $\mathrm{e}$ recursos que podem ser criados com tais ferramentas são: textos, planilhas, slides, animações e questionários.

No menu materiais, ficam os materiais produzidos pelos usuários e postados no respectivo ambiente, ainda há o menu notícias, onde o mesmo pode ser usado para informar os usuários sobre o desenvolvimento do ACREA e inovações com o uso de REAs.

No menu Exemplos de REAs, serão colocados alguns exemplos de recursos digitais, de forma que o usuário possa entender melhor o que são esses recursos, além de possuir um menu Conceitos, onde é dado os principais conceitos sobre REAs e FLOSS.

É possível ainda acessar os diagramas modelados. Possui o menu sugestões para que os usuários possam apresentar comentários, críticas e sugestões de melhorias ao ACREA.

\section{Conclusão}

Busca-se com o ACREA facilitar a busca e compartilhamento de REAs, de forma simples e prática para disseminação do conhecimento, reunir notícias, materiais de estudo sobre o assunto e incentivo a práticas educacionais abertas.

O ACREA atenderá as reais necessidades de professores, alunos e demais interessados, pois esse foi pensado a partir de anseios de docentes por meio de pesquisa realizada. Poderá também se tornar referência para a comunidade de SL e de professores na busca de REAs e materiais de apoio ao aprendizado porque busca satisfazer aos princípios de SL e liberdades de REAs.

Conclui-se então que o ACREA poderá oferecer possibilidades para produção e compartilhamento de REAs, que possa ser utilizado por alunos, professores, servidores e demais interessados, implementado de acordo com as necessidades desses usuários e que satisfaça aos princípios de SL e as liberdades de REAs. Assim como difundir a ideia.
No entanto, apresenta como possibilidades de trabalhos futuros a implementação de uma ferramenta de autoria integrada ao ACREA baseada em IMS-LD, com possibilidade de integração aos AVA e RSE, e compatível com outras ferramentas existentes baseadas em IMS-LD.

Sugere-se também a continuidade do trabalho com a implementação de uma rede social para que docentes possam compartilhar suas experiências e necessidades sobre REAs, de tal forma que possam utilizar o ACREA como suporte às ações docentes, já que essa pode ser uma maneira de promover o uso de REAs e, por conseguinte, a porta de entrada para o desenvolvimento de REAs.

\section{Referências}

ABDO, A. H. Educação aberta, a luta pelo mais humano dos direitos - Wikiversidade. 2011. Disponível em: http://goo.gl/zKgIsA. Acesso em: 11 de novembro de 2014.

AMIEL, T.; OREY, M.; WEST, R. E. Recursos educacionais abertos (REA): modelos para localização e adaptação. ETD: Educação Temática Digital, n. 12, p. 112-125, 2011.

BEZERRA, E. Princípios de análise e projeto de sistemas com UML. $3^{\text {a }}$ ed. Rio de Janeiro: Elsevier, 2014.

DUTRA, R. L. S.; TAROUCO, L. M. R. Recursos Educacionais Abertos (Open Educational Resources). RENOTE: revista novas tecnologias na educação, v. 5, n. 1, 2007.

FLICK, U. Uma introdução à pesquisa qualitativa - um guia para iniciantes. Tradução: Magda Lopes. Revisão técnica: Dirceu Silva. Porto Alegre: Penso, 2013.

FSF, FREE SOFTWARE FOUNDATION. Libre Documentation Explained. 2007. Disponível em: https://www.gnu.org/gwm/libredocxml/x53.htm 1. Acesso em: 11 de novembro de 2014. 
(MATIAS et al., 2016)

HEUSER, C. A. Projeto de banco de dados. Série Livros didáticos informática UFRGS. Vol. 4. Porto Alegre: Bookman, 2009.

HILEN, J. Open Educational Resources: Opportunities and Challenges. OECD's Centre for Educational Research and Innovation. Disponível em: <http://www.oecd.org/dataoecd/5/47/37351085. pdf > . Acesso em: 15 de dezembro de 2014.

IMS, IMS GLOBAL LEARNING CONSORTIUM INC. IMS Learning Specification: Information Model, 2003. Disponível em: http://www.imsglobal.org/learningdesign.

Acesso em: 26 de maio de 2015.

LIANG, L. Guide to open content licenses. Roterdam: Piet Zwart Institute, 2004. Disponível em: http://pzwart.wdka.hro.nl/mdr/research/lliang/ open_content_guide. Acesso em: $22 \mathrm{de}$ dezembro de 2014.

MALLMANN, E. M.; JACQUES, J. S. Recursos Educacionais Abertos (REA) na Pedagogia do e-Learning. In: ROSADO, L. A. S.; FERREIRA, G. M. S.; Educação e tecnologia: parcerias. Vol. 4. Rio de Janeiro: Editora Universidade Estácio de Sá, 2015.

MALLMANN, E. M.; JACQUES, J. S.; SONEGO, A. H. S.; TEIXEIRA, T. G.; TOEBE, I. C. D. DOMINGUES, F. R. Potencial dos recursos educacionais abertos para integração das tecnologias e convergência entre as modalidades na UFSM. Revista Eletrônica de Educação, v. 7, n. 2, p. 263-284, 2013. Disponível em: http://dx.doi.org/10.14244/19827199742.

Acesso em: 25 de dezembro de 2014.

MARCONI, M. A.; LAKATOS, E. M. Técnicas de pesquisa. São Paulo: Atlas, 2002.

MAXIM, B. R.; PRESSMAN, R. S. Engenharia de software - uma abordagem profissional. $8^{\mathrm{a}}$ ed. Porto Alegre: Bookman, 2016.
MERRIL, M. D. Knowledge objects and mental models. In: WILEY, D. A. (org.). The Instructional Use of Learning Objects. 2000. Versão online. AIT/AECT. Disponível em:<http://reusability.org/read/>; Acesso em: 22 de dezembro de 2014.

OLIVEIRA, F. K.; ABREU, K. F. O estado da arte dos recursos educacionais abertos. In: ABREU, K. F. (orgs.). Múltiplos olhares sobre o agir científico do Campus Salgueiro. Recife: Pipa Comunicação, 2016.

OLIVEIRA, F. K.; ABREU, K. F; SILVA, A. A. G. Formação profissional em recursos educacionais abertos. Revista Semiárido De Visu, v. 3, n. 2, p. 98-109, 2015. Disponível em: $\quad$ http://periodicos.ifsertaope.edu.br/ojs2/index.php/revista/article/view/20 5. Acesso em: 30 de abril de 2016.

OLIVEIRA, F. K.; GOMES, A. S. Recursos educacionais abertos: materiais auxiliares à prática tutorial. In: OLIVEIRA, F. K.; ABREU, K. F. (orgs.). Experiências de pesquisas em tecnologia e educação. Recife: Pipa Comunicação, 2015a.

OLIVEIRA, F. K.; GOMES, A. S. A development model of units of learning for multiple platforms. In: Information Systems and Technologies (CISTI), 2015 10th Iberian Conference on. IEEE, 2015b. p. 1-6. Disponível em: Acesso em: 29 de junho de 2015.

Software livre como SAAS para compartilhamento de REA. In: OLIVEIRA, F. K.; ABREU, K. F. (orgs.). Experiências de pesquisas em tecnologia e educação. Recife: Pipa Comunicação, 2015c.

OLIVEIRA, F. K.; SANTANA, J. R.; PONTES, M. G. O.; CUNHA, R. B. O ensino de geometria por meio de múltiplas plataformas: uma experiência com o Geonext. Revista de Ensino de Ciências e Matemática, São Paulo, V. 2, N. 1, jun., 2011. Disponível em:

$\underline{\text { http://revistapos.cruzeirodosul.edu.br/index.php }}$ 
/rencima/article/view/49. Acesso em: 22 de dezembro de 2014.

OLIVEIRA, F. K. O vídeo pela internet como ferramenta educacional no ensino da Geometria. 2010. 102f. Dissertação (Programa de Pós-Graduação em Ciências da Computação) - UECE, Fortaleza, 2010.

PAULA FILHO, W. P. Engenharia de Software: fundamentos, métodos e padrões. $3^{\mathrm{a}}$ ed. Rio de Janeiro: LTC, 2009.

REINEHR, R. Recursos educacionais abertos na aprendizagem informal e no autodidatismo. In: SANTANA, B.; ROSSINI, C.; PRETTO, N. L. Recursos Educacionais Abertos: práticas colaborativas políticas públicas. São Paulo: EDUFBA, p. 153-176, 2012.

ROSEN, L. Open Source License: Software Freedom and Intellectual Property Law. Upper Saddle River, NJ: Prentice Hall, 2005.

TAURION, C. Software livre: potencialidades e modelos de negócio. São Paulo: Brasport, 2004.

WILEY, D. A. The Current State of Open Educational Resources. 2005. Disponível em: <http://www.oecd.org/document/32/0,2340, en_2649_33723_36224352_1_1_1_1,00.html>. Acesso em: 12 de outubro de 2014.

WILEY, D. A.; GIBBONS, A.; RECKER, M. A reformulation of the issue of learning object granularity and its implications for the design of learning objects. The instructional use of learning objects. Bloomington, Indiana: Agency for Instructional Technology and Association for Educational Communications of Technology, 2000. Disponível em: <http://reusability.org/granularity.pdf>. Acesso em: 15 de outubro de 2014. 